\title{
Research Article \\ Seismic Behaviour of Buried Pipelines: 3D Finite Element Approach
}

\author{
Smrutirekha Sahoo, Bappaditya Manna, and K. G. Sharma \\ Department of Civil Engineering, Indian Institute of Technology Delhi, New Delhi 110016, India \\ Correspondence should be addressed to Smrutirekha Sahoo; s.sahoo.iitd@gmail.com
}

Received 13 April 2014; Revised 27 June 2014; Accepted 7 July 2014; Published 5 August 2014

Academic Editor: Vladimir Sokolov

Copyright (C) 2014 Smrutirekha Sahoo et al. This is an open access article distributed under the Creative Commons Attribution License, which permits unrestricted use, distribution, and reproduction in any medium, provided the original work is properly cited.

This paper presents a numerical investigation on six pipeline models to study the seismic response of single and double buried pipelines using finite element method. Different depth and spacing of pipes are considered to investigate their prominent role in the seismic response of buried pipelines under an earthquake loading having PGA of $0.2468 \mathrm{~g}$. In case of single pipeline, the maximum magnitude of final displacement as well as the stress at the end of the seismic sequence is found at the burial depth equal to the pipe diameter. In case of double pipeline, the maximum magnitude of final displacement is found when the spacing between pipes is equal to half the pipe diameter and there is an increasing tendency of developed stress with increase in spacing between pipes. In addition to the above results, the response of the buried pipelines with a particular bend angle (artificially induced bend/buckle) to the permanent ground deformation which is assumed to be the result of seismic wave propagation has also been studied. Remarkable differences in these results are obtained and with these results the designers can reduce seismic risk to their buried pipelines by taking proper precautionary measures.

\section{Introduction}

Earthquakes are one of the most destructive natural hazards which can severely damage several lifeline utilities in both urban and nonurban areas. The potential damage because of earthquakes has been intensified with the rapid growth of urbanisation, hence the initiation of recovery efforts is required to restore some of the indispensable services like lifeline utilities by identifying the most vulnerable areas to limit the impact of structural as well as human damage and destruction caused by intensive earthquakes. These lifeline utilities include water supply, sewage system, and oil and gas supply pipelines, whose failure could worsen the damages due to earthquakes. For example, in case of gas and petroleum transferring pipelines, other than the economic loss and contamination of the ecosystem, leakage of gas or oil from the damaged pipelines would cause fires in case of electricity sparks as discussed by Scawthorn and Yanev [1]. In addition, the destruction of water pipelines could prevent the fire fighter's activities to make the fire under control. The 1989 Loma Prieta earthquake [2], 1994 Northridge earthquake [3], and 1995 Kobe earthquake [4] were the famous examples of lifeline failures which drew more attention towards the investigation of circumstances that cause pipeline failures. In 1999 Chi-Chi earthquake, the urban subway system of Taipei encountered damages [5]. The seismic behaviour of buried pipeline under earthquake conditions has been investigated by many researchers [6-9]. The response of buried pipeline to lateral ground movements is critical for design and risk evaluation in a variety of adverse environmental conditions which also include earthquake induced faulting as stated by various researchers [10-12]. The soil stresses and deformations, which in practice are difficult to characterize, are the main factors in finding the seismic response of buried pipelines. Each source of ground movement (e.g., earthquake) can cause significant pipeline strain by means of (1) bending and (2) increased longitudinal friction from high lateral soil stresses. Permanent ground displacement (PGD) is a substantial source of damage to water facilities $[13,14]$. Types of PGD include fault rupture, settlement, subsidence/uplift, and liquefaction induced lateral spreading or landslides deformations. Damage occurring to water and 
gas pipelines during PGD has been well documented by several researchers in the literature $[15,16]$. The damage to pipelines caused by the San Fernando earthquake in 1971 has been evaluated and it is concluded that almost half of the total pipeline damage occurred in specific areas where fault rupture was observed [17]. In view of these findings and the uncertainties, a series of numerically developed models are analysed on six pipeline models with different burial depth and spacing parameters. The effect of the depth and spacing on the seismic response of the buried pipelines has been examined and also the response of the pipelines to the earthquake induced PGD has also been addressed.

\section{Details of the Numerical Model}

Three-dimensional solid numerical models are developed for the simulation of soil consisting pipeline models with different depth and spacing. In each model, the hollow steel pipeline is surrounded by gravelly soil and then sandy soil is provided around the gravelly soil. The pipelines are modelled as two-dimensional elastic plate structures. The outer diameter (designated as " $D$ " in Figures 1 and 2) and the thickness of the pipelines used in FE analysis are considered as $2.1 \mathrm{~m}$ and $0.015 \mathrm{~m}$, respectively. The water table is assumed to be at the ground level. The water pressure on the surface of pipeline from inside due to the flow of water in the pipeline is considered as $25 \mathrm{kN} / \mathrm{m}^{2}$. The material parameters of soil and pipeline adopted for the FE analysis are shown in Table 1. The Mohr-Coulomb model is adopted for soil to simulate the elastoplastic behaviour of soil. The interface elements are created around the pipeline by calculating the normal stiffness modulus, shear stiffness modulus, cohesion, internal friction angle, and the assumed strength reduction factor from the material properties of soil and pipe to provide the interface between soil and pipe. In this study, the damping constants, that is, " $c_{p}$ " and " $c_{s}$ ", required for the time-history analysis are calculated as follows [18]:

$$
\begin{gathered}
C_{p}=\rho \cdot A \cdot \sqrt{\frac{\lambda+2 G}{\rho}}=W \cdot A \cdot \sqrt{\frac{\lambda+2 G}{W \cdot 9.81}}=c_{p} \cdot A \\
C_{s}=\rho \cdot A \cdot \sqrt{\frac{G}{\rho}}=W \cdot A \cdot \sqrt{\frac{G}{W \cdot 9.81}}=c_{s} \cdot A,
\end{gathered}
$$

where $\lambda=v E /((1+v)(1-2 v))$ and $G=E /(2(1+v))$. $A$ is crosssectional area $\left(\mathrm{m}^{2}\right) ; E$ is modulus of elasticity $\left(\mathrm{kN} / \mathrm{m}^{2}\right) ; W$ is unit weight $\left(\mathrm{kN} / \mathrm{m}^{3}\right) ; \lambda$ is volumetric modulus of elasticity $\left(\mathrm{kN} / \mathrm{m}^{2}\right) ; G$ is shear modulus $\left(\mathrm{kN} / \mathrm{m}^{2}\right)$; and $\nu$ is Poisson's ratio.

In FE analysis, the meshing for soil elements has been done using 10-noded tetrahedron elements whereas, for the plate elements of pipeline, 8-noded quadratic element meshing is chosen. The boundary conditions have also been provided as it is well known that the accuracy and stability of any FE based computation depend on the boundary conditions. In this paper, two types of boundary conditions are considered: free-roller and full-fixity. The free-roller and the full-fixity boundary condition are considered for the side soil boundary nodes and the bottom soil boundary nodes, respectively. At the free-roller boundary which is usually used to represent a far field boundary condition, soil particles are free to move in the direction which is parallel to the wall boundary. The geometry and generated mesh with the boundary conditions of a single and a double pipeline model are shown in Figures 1 and 2, respectively. All the six models developed using the finite element method with different depth and spacing parameters are analysed under a seismic excitation having PGA as $0.2468 \mathrm{~g}$. The time history data having PGA as $0.2468 \mathrm{~g}$ adopted during the numerical analysis are chosen from the available inbuilt earthquake histories in the finite element software, MIDAS/GTS [18]. The time history of the acceleration chosen for the finite element analysis is shown in Figure 3. These data are used in finite element analysis to provide unidirectional seismic excitation (i.e., lateral to the orientation of pipeline and here it is along the $x$-direction in Figures 1 and 2). The reason behind the lateral directional seismic excitation is its criticality in terms of both stress and deformation magnitudes in comparison to longitudinal (along the axis of pipe) seismic excitation of the buried pipelines. Hence the response of the buried pipelines to the lateral directional seismic excitation is taken into consideration for the present analysis.

In this research, behaviour of both single and double buried pipelines under the effect of PGD has also been included using finite element models idealized with shell elements. A bend has been manually created at the centre of the pipeline with a particular bend angle, that is, $30^{\circ}$, which has been assumed to be the result of permanent ground deformation as a result of the seismic excitation [19]. The outline of the model is shown in Figure 4. Figure 4 also shows the image of parameters where the bend angle is kept as $30^{\circ}$ while all other parameters like radius of bend and the PGD encounter angle remain fixed for all the cases.

\section{Results and Discussions}

The effect of depth in case of single pipeline and the effect of spacing between pipelines in case of double pipeline shown in Figures 5 and 6 to examine the pipe stress and the deformation behaviour of the pipeline under an earthquake loading having PGA of $0.2468 \mathrm{~g}$ are studied in detail as follows.

3.1. Effect of Depth in Case of Single Pipeline. One of the varying factors in this study is the burial depth of pipe. Three analyses have been carried out on the single pipeline with outer diameter as $2.1 \mathrm{~m}$ and thickness as $0.015 \mathrm{~m}$ at different depths of $1.05 \mathrm{~m}, 2.1 \mathrm{~m}$, and $4.2 \mathrm{~m}$ (i.e., $D / 2, D$, and $2 D$, resp.) under the acceleration record as depicted in Figure 3 with PGA of $0.24 \mathrm{~g}$. The final displacement found at the end of the seismic sequence along the length of pipeline is plotted in Figure 5. The maximum stress induced in the pipeline versus the normalized burial depth is plotted in Figure 6. It is found from Figure 5 that the magnitude of final displacement for all the cases is higher at the middle portion and decreases gradually towards the end portions 


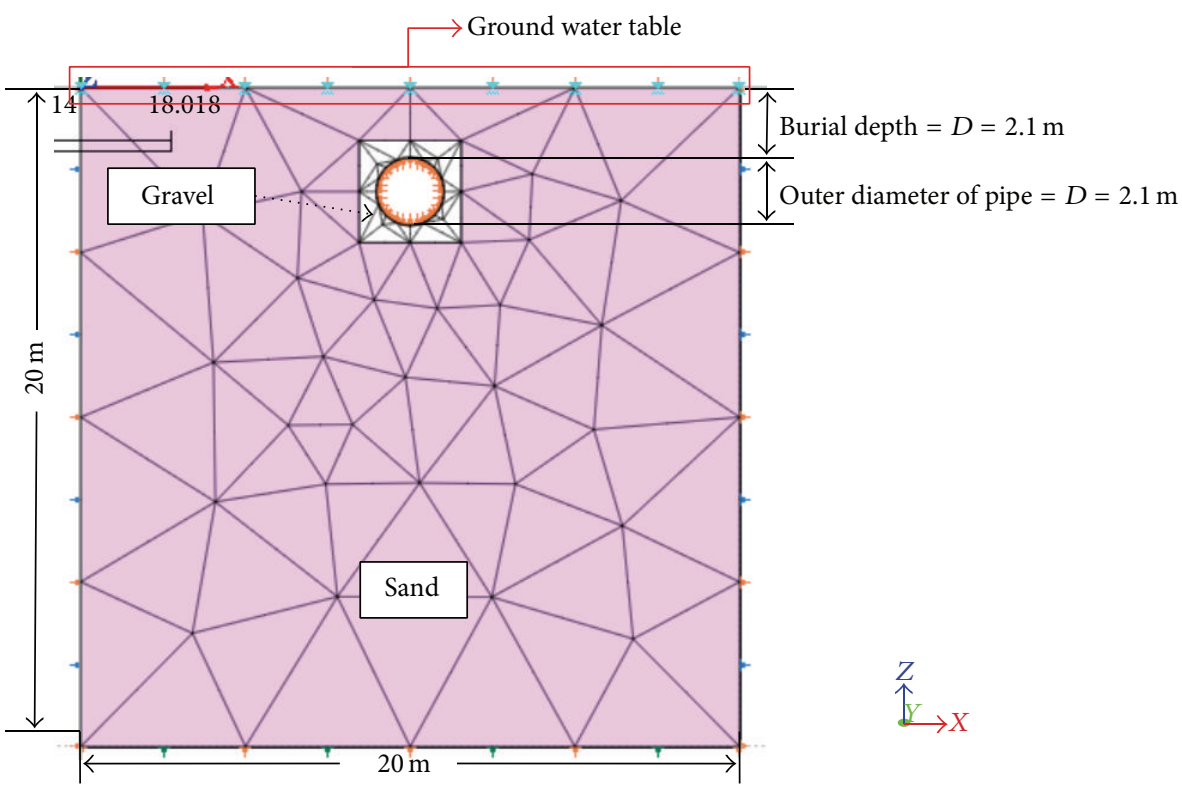

(a)

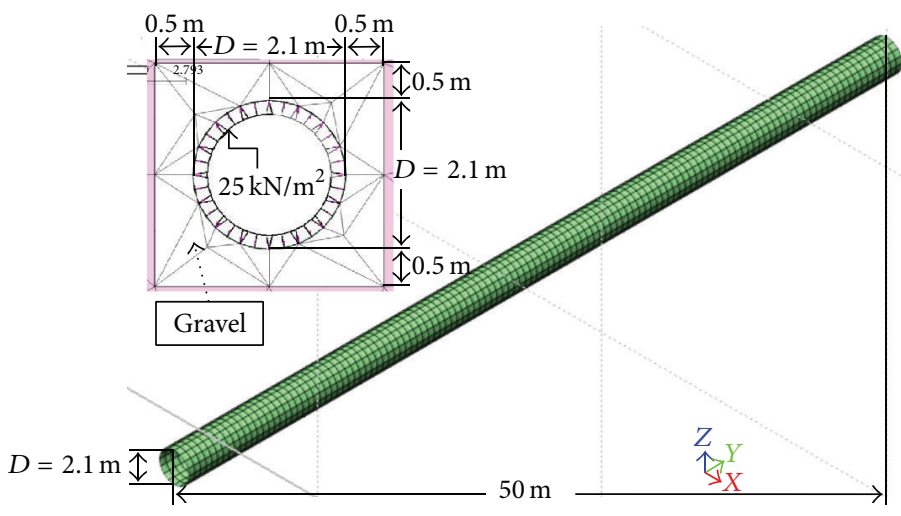

(b)

FIGURE 1: FE modelling of the single pipeline (pipe depth = D). (a) Front view of the whole model in $X Z$ plane and (b) 3-dimensional view of the pipeline.

TABLE 1: Material properties of soil and pipeline.

\begin{tabular}{lccc}
\hline Parameters & Sand & Gravel & Steel pipe \\
\hline Modulus of elasticity $(E), \mathrm{kN} / \mathrm{m}^{2}$ & 3500 & 18000 & 200000000 \\
Poisson's ratio $(\nu)$ & 0.35 & 0.33 & 0.3 \\
Unit weight $(\gamma), \mathrm{kN} / \mathrm{m}^{3}$ & 18 & 19.5 & 75 \\
Cohesion $(c), \mathrm{kN} / \mathrm{m}^{2}$ & 0 & 0 & - \\
Frictional angle $(\phi)$ & 25 & Mohr-Coulomb & - \\
Model type & Mohr-Coulomb & Elastic \\
\hline
\end{tabular}

of the pipeline. The pattern of displacement curves along the length of pipeline at each burial depth in case of single pipeline is similar in nature. The magnitude of displacement is maximum at the burial depth equal to the diameter of the pipe whereas it is minimum at the burial depth equal to half the diameter of the pipe. From Figure 6, it is quite clear that the magnitude of stresses developed on both top and bottom plates in case of single pipelines is maximum at the depth equal to the diameter of the pipe and both the curves followed a similar pattern.

Hence it is safer to avoid the installation of a pipeline at the burial depth equal to the diameter of pipeline. Hence 


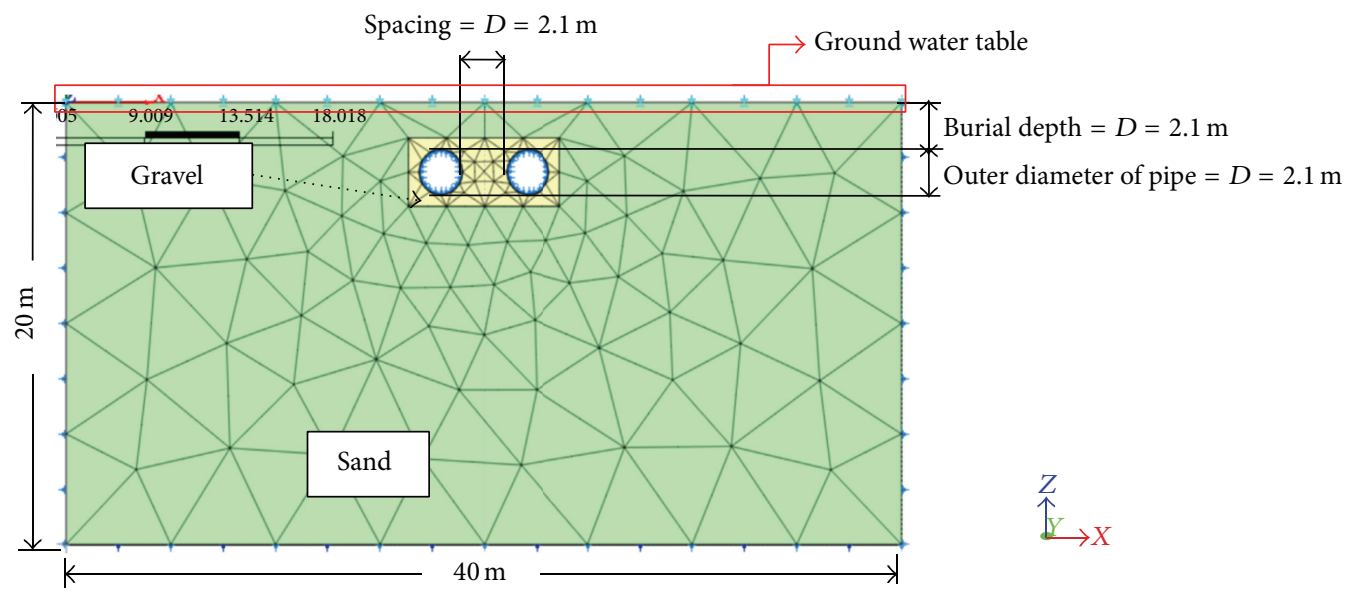

(a)

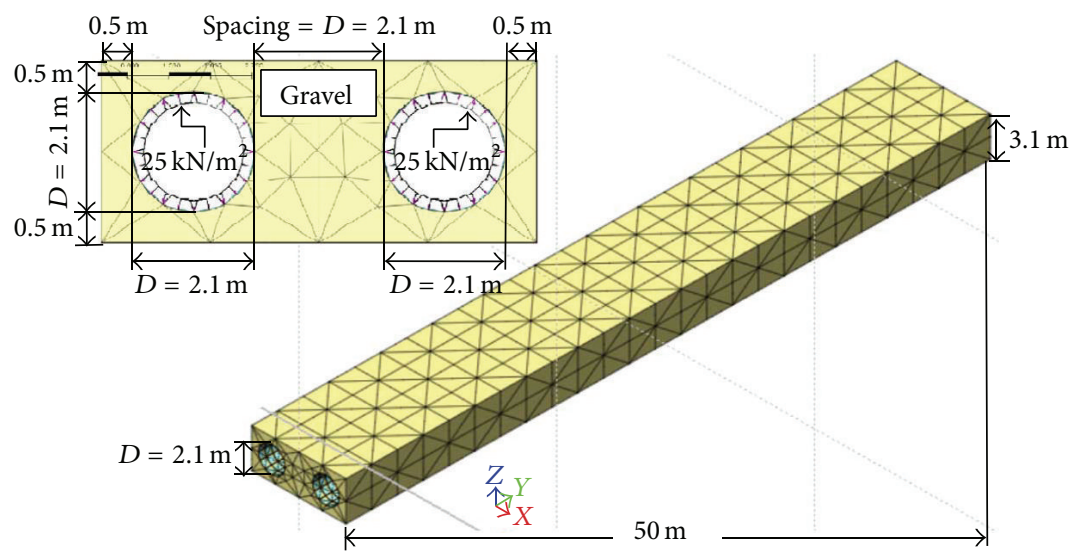

(b)

Figure 2: FE modelling of double pipeline (pipe depth $=D$; pipe spacing $=D$ ). (a) Front view of the whole model in $X Z$ plane and $(b)$ 3-dimensional view of both the pipelines.

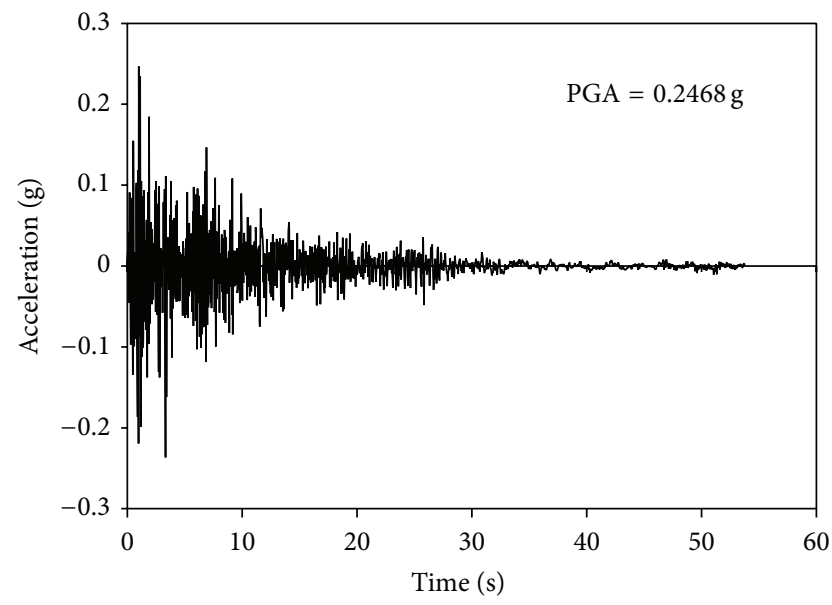

Figure 3: History of acceleration, 1940, EL, Centro Site, Vertical [18].

the magnitude of displacement of pipeline as well as the magnitude of stress induced in the pipeline at the end of the seismic sequence can be minimized. These results are in good agreement with the results of Azadi and Mir Mohammad Hosseini [20].

3.2. Effect of Spacing between Pipelines in Case of Double Pipeline. Another varying factor in this study is the spacing between pipelines. Three analyses are carried out on the double pipelines with fixed burial depth of $D$ having outer diameter as $2.1 \mathrm{~m}$ and thickness as $0.015 \mathrm{~m}$ at different spacing of $1.05 \mathrm{~m}, 2.1 \mathrm{~m}$, and $4.2 \mathrm{~m}$ (i.e., $D / 2, D$, and $2 D$, resp.) under the acceleration record as depicted in Figure 3 . It is found from Figure 5 that the magnitude of final displacement for all the cases is higher at the middle portion and decreases gradually towards the end portions of the pipeline. The pattern of displacement curves along the length of pipeline for each spacing variation in case of double pipeline is similar in nature. The magnitude of displacement is maximum with the spacing between pipes equal to half the diameter of the pipe whereas it is minimum with the spacing between pipes equal to the diameter of the pipe. 


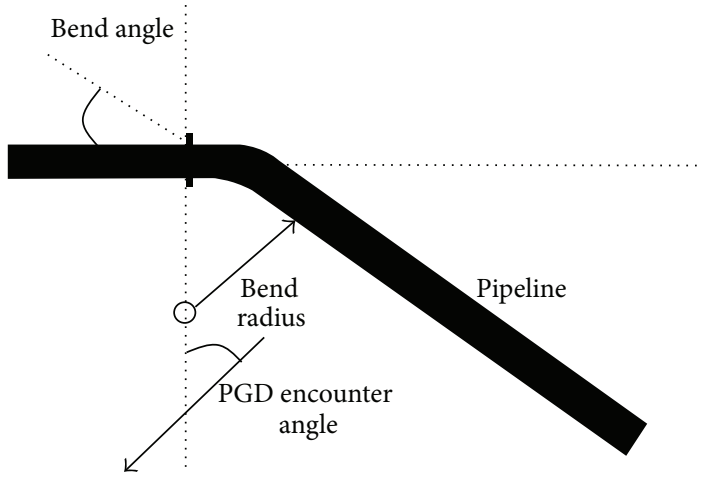

(a)

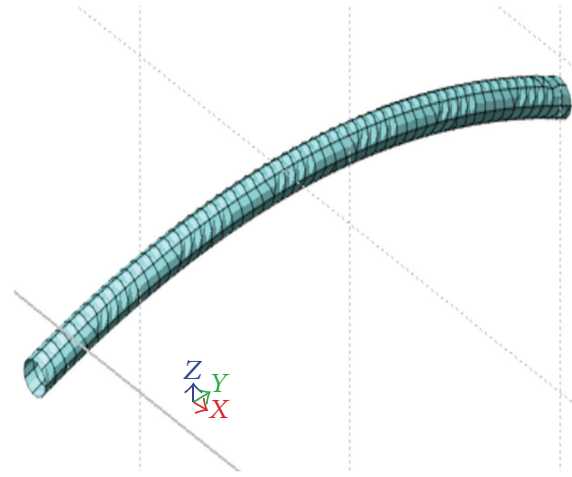

(b)

Figure 4: (a) Image of parameters taken to create a bend with bend angle of $30^{\circ}$ in the pipeline in the $y$ - $z$ plane and (b) 3-dimensional FE modelling of the single bend pipeline (pipe depth $=D$ ).

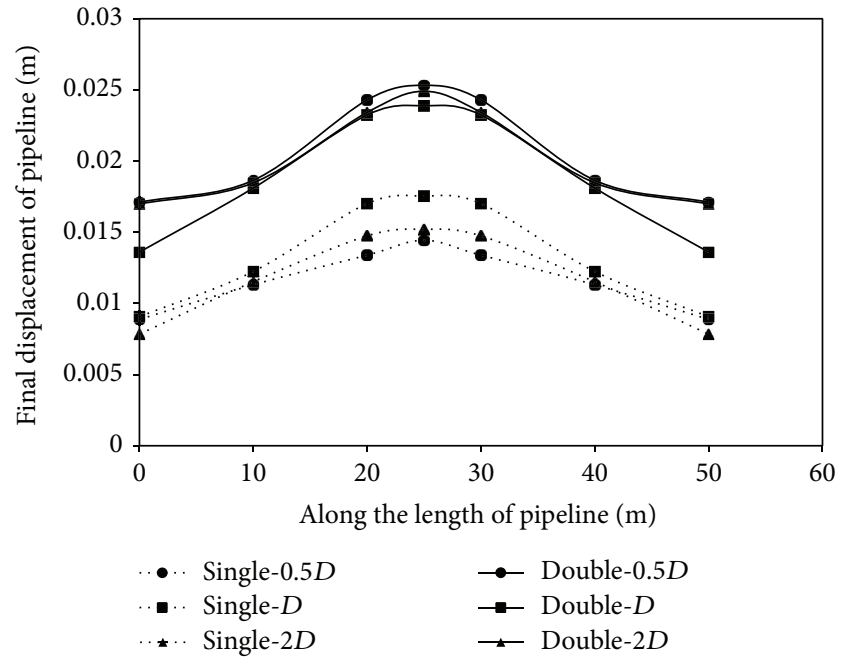

Figure 5: Variation of burial depth and spacing of pipes with the maximum displacement of pipelines at the end of the seismic excitation.

From Figure 6, it is quite clear that the magnitude of stress on pipelines increases with increase in spacing between pipes. It has also shown that the magnitude of stresses developed on both top and bottom plates in case of double pipelines is maximum with the spacing between pipes equal to double the diameter of the pipe and both the curves followed a similar pattern. Hence it is better to provide a spacing between pipes equal to the diameter of the pipe in case of installation of double pipeline with the burial depth equal to the diameter of pipe. This can help in maintaining the magnitude of displacement of pipelines to the minimum and in avoiding the maximum magnitude of stress induced in the pipeline at the end of the seismic sequence. The final deformed diagram of all the pipeline models at the end of the seismic sequence having $\mathrm{PGA}=0.2468 \mathrm{~g}$ has been shown schematically with

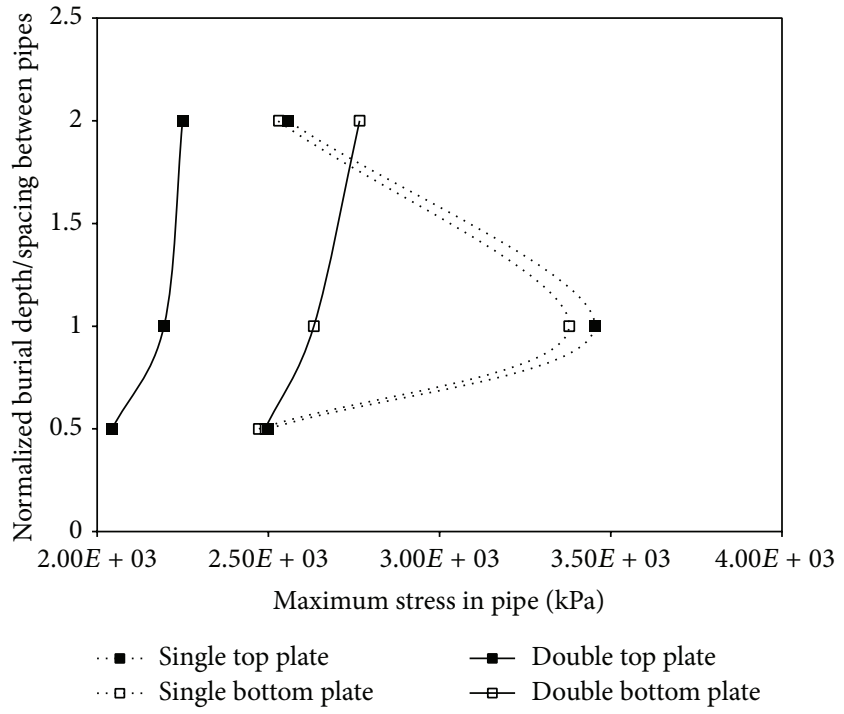

FIGURE 6: Variation of burial depth and spacing of pipes with the maximum stresses in pipelines at the end of the seismic excitation.

the contour diagrams in Figures 7(a)-7(c) and Figures 7(d)7(f) for single and double pipeline, respectively. From Figures $7(\mathrm{a})-7(\mathrm{f})$, it can be seen that the zone of maximum deformation along the length of the pipeline is found around middle portion of the pipelines and decreases gradually towards the ends. The reason behind this kind of deformities can be the direction of seismic excitation applied to the pipelines. Because when the direction of seismic excitation was along the longitudinal direction of the pipelines, the deformities were distributed all over the pipe length rather than concentrating only on the middle portion.

3.3. Effect of PGD on Buried Pipelines and Bends. In addition to the above results, the response of the buried pipelines to the permanent ground deformation (PGD) has also been 


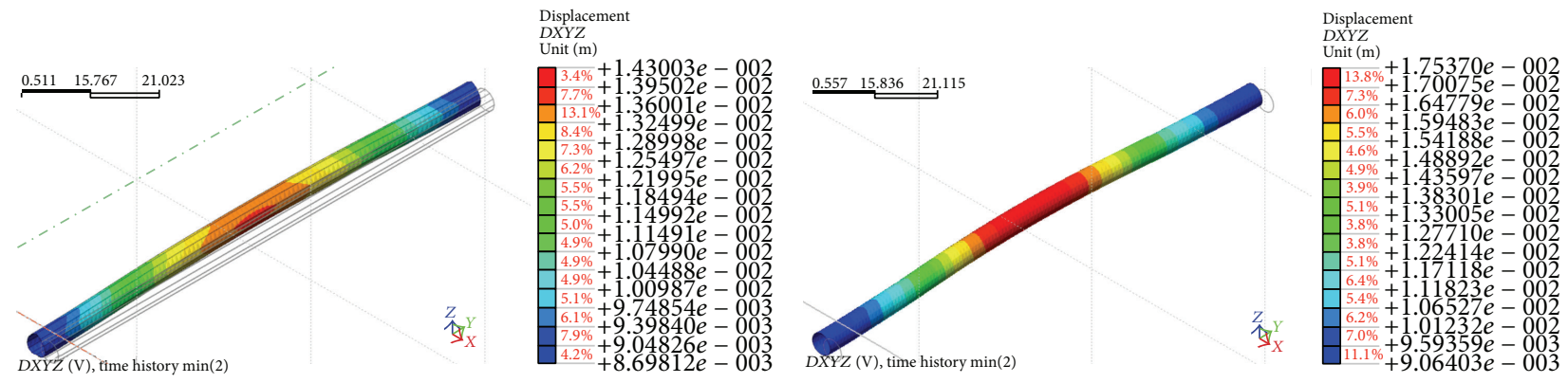

(a)

(b)

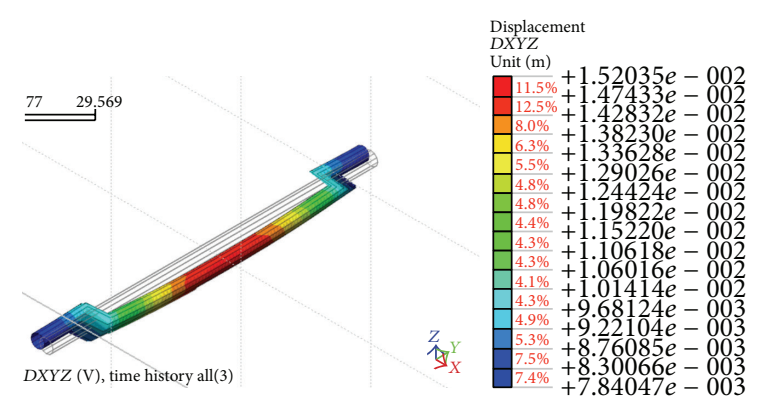

(c)

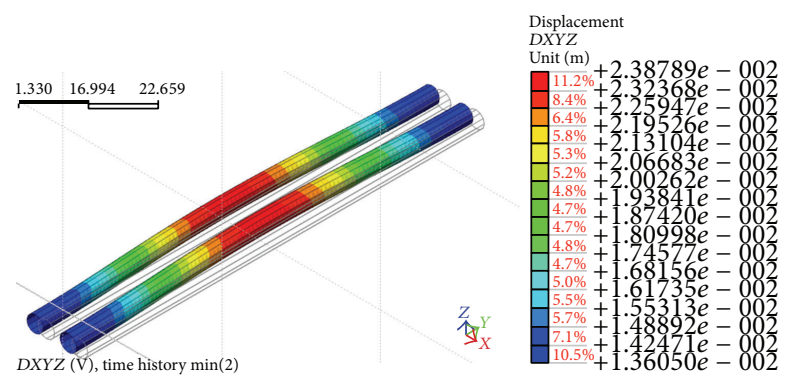

(e)

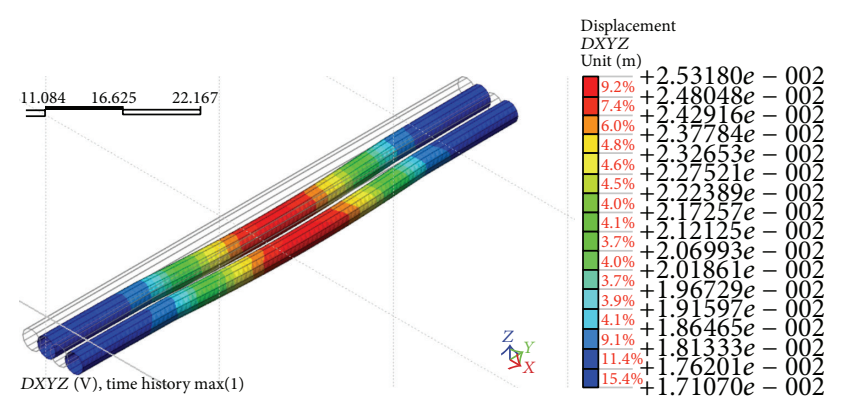

(d)

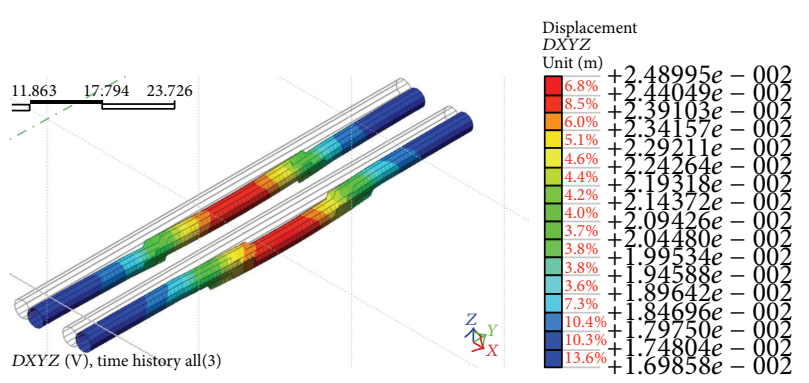

(f)

Figure 7: Deformed diagram of single and double pipeline at the end of the seismic excitation. (a) Burial depth $=0.5 D$, (b) burial depth $=D$, (c) burial depth $=2 D$, (d) spacing $=0.5 D$, (e) spacing $=D$, and (f) spacing $=2 D$.

studied by creating a bend in the pipeline which is assumed to be the result of earthquake induced permanent ground deformation. To include this issue in the present FE analysis regarding the response of the buried pipelines to PGD, the final deformation of the pipeline observed at the end of the seismic excitation and a bend with a bend angle of $30^{\circ}$ has been manually applied to the pipeline models for all cases.

Nonlinear static analysis has been carried out on both straight and bend pipelines after the seismic excitation to observe the pipe axial strain for all the cases with different burial depth and spacing. Hence the effect of different burial depths and spacing of pipelines to the PGD induced bend has been addressed in terms of displacement as well as axial strain in Figures 8 and 9, respectively.

From Figure 8 it is found that, in case of single pipeline, there is no variation in the magnitude of maximum displacement with the burial depth of pipe for the straight pipe case. But for the bend pipe case, a very high displacement has been observed with the burial depth of $0.5 \mathrm{~d}$ which is beyond the yield limit of the pipe and then it decreases and becomes constant with further increase in the burial depth of bend pipe. In case of double pipe also, no variation in the magnitude of maximum displacement with the spacing between pipes has been found for the straight pipe case. But for the bend pipe case, the curve clearly indicates that there is a steady increase in the magnitude of displacement with increase in the spacing between pipes. It has also been observed that the magnitude of maximum displacement in case of straight pipe is very small as compared to the bend pipe for both cases of single and double pipelines.

In Figure 9 the exact same tendency to that of Figure 8 has been found. It means that a similar tendency of developed strain like that of the maximum displacement has been found for both straight and bend pipe cases in both single and double pipes. The only thing to be observed from Figure 9 is that no development of strain has been found in case of 


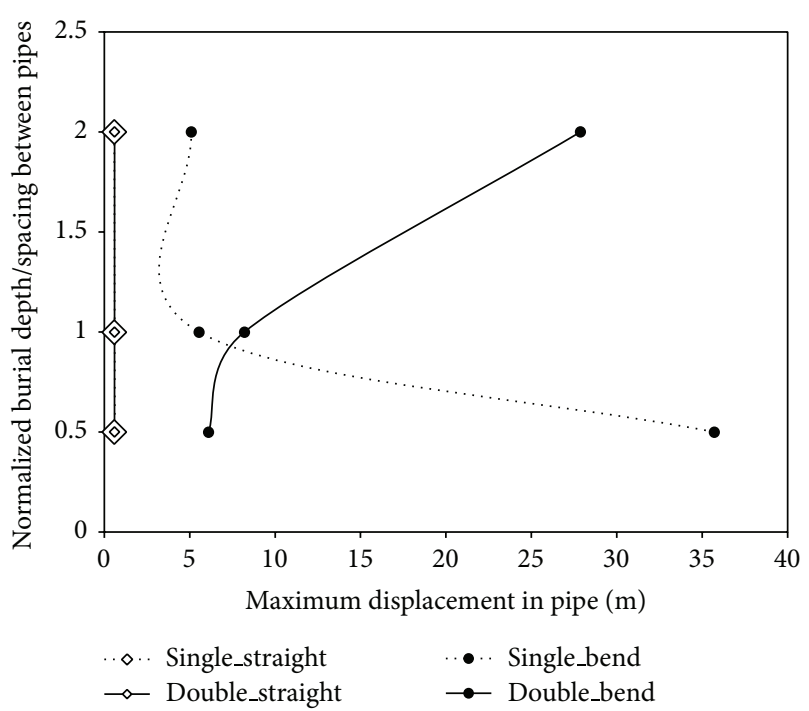

FIGURE 8: Variation of burial depth and spacing of pipes with the maximum displacement in pipelines at the end of the nonlinear static analysis.

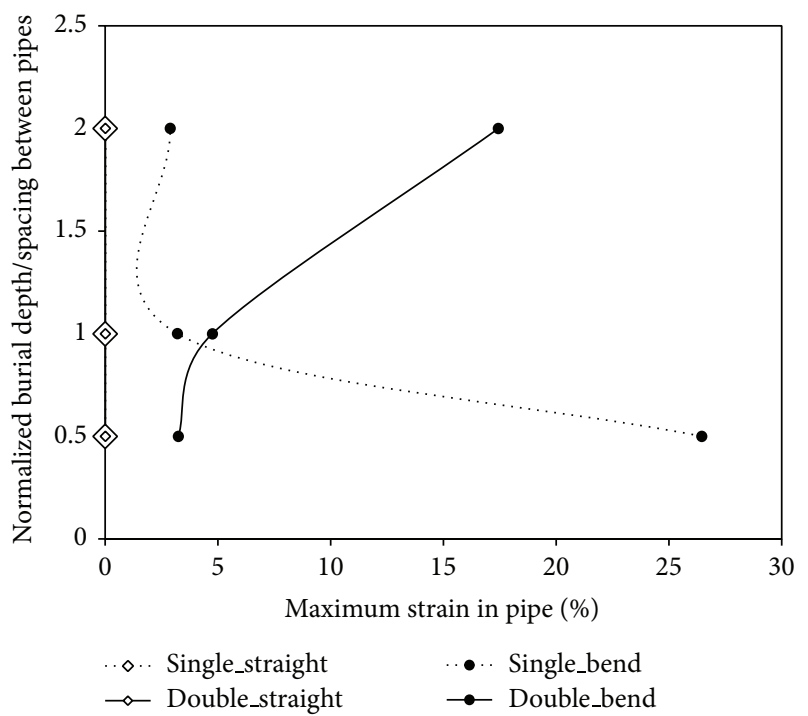

Figure 9: Variation of burial depth and spacing of pipes with the maximum strain observed in pipelines at the end of the nonlinear static analysis.

straight pipe for both single and double pipelines. But the maximum percentage of strain is found in single bend pipe with burial depth of $0.5 \mathrm{~d}$, that is, around $26 \%$, whereas in case of double bend pipe the maximum percentage of strain is found for the spacing between pipes of $2 \mathrm{~d}$, that is, around $17 \%$.

The final deformed diagram of all the bend pipeline models at the end of the nonlinear static analysis has been shown schematically with the contour diagrams in
Figures 10(a)-10(c) and Figures 10(d)-10(f) for single and double pipeline, respectively. From Figures 10(a)-10(f), it can be seen that the zone of maximum deformation along the length of the pipeline is found at the end portion of the pipelines where the bend is maximum and decreases gradually towards the straight ends. The reason behind this kind of deformities can be the type of pipelines used, that is, thin walled, and the bend in the pipeline. Since the thin walled pipe and the bend portion of the pipe (behave like hanging through the soil) have lesser moment of inertia, so they can be easily bent and deformed to accommodate the soil displacement without allowing any large geometric deformation to the pipe.

\section{Conclusions}

The current analyses have been performed to understand the effect of burial depth and spacing between pipes on the seismic response of buried pipelines and the following conclusions have been made.

The larger magnitude of displacement is found at the middle portion of the pipeline than at the end portions for all the cases and this can be due to the boundary conditions and the direction of seismic excitation provided during the FE analysis. It is found that the magnitude of stress is maximum at the burial depth equal to the diameter of the single pipeline whereas it is having an increasing tendency with increase in spacing between pipes in case of double pipeline. The magnitude of displacement reaches its maximum value when the burial depth of pipe is equal to the pipe diameter in case of single pipeline whereas it is maximum when the spacing between pipes equals to half the pipe diameter in case of double pipeline.

Hence it can be concluded that avoiding the burial depth of pipe equal to the pipe diameter can be more effective from design point of view. In case of double pipeline, the reason behind the larger magnitude of displacement with spacing between pipes equal to half the diameter of pipe than the other larger spacing magnitudes is due to the overlapping effect of the stress zones of the individual pipelines with lesser spacing. It is more effective in providing the spacing between pipes equal to the pipe diameter during the installation of a double pipeline. Hence the results obtained on the above mentioned parameters can be kept in mind while designing buried pipelines to achieve both safety and economy. The reason behind the larger magnitude of displacement with spacing between pipes equal to half the diameter of pipe than the other larger spacing magnitudes in case of double pipeline is due to the overlapping effect of the stress zones of the individual pipelines with lesser spacing.

It can also be concluded that to lessen the vulnerability of geometric failure of pipes as a result of earthquake induced PGD, one should avoid the shallower burial depth in case of design of pipelines. The burial depth nearly equal to the diameter of pipe can be considered as safe as well as economical for both single and double pipes. Also providing very strong confinement around the pipes as well as considering flexible 


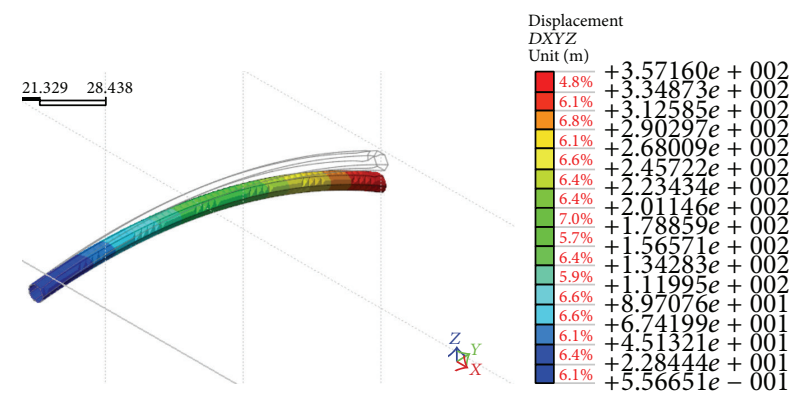

(a)

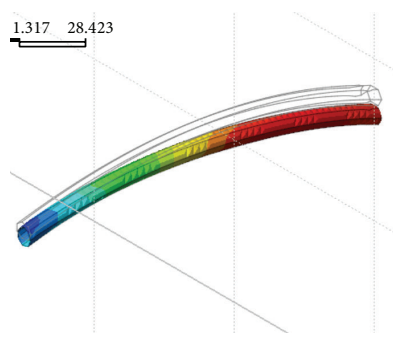

(c)
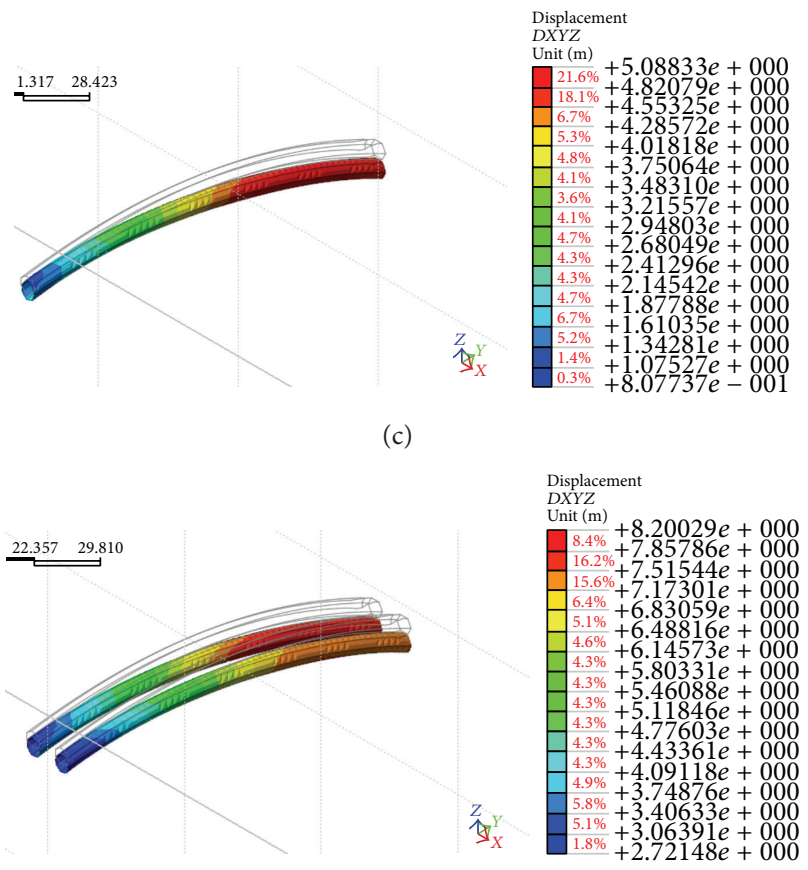

(e)

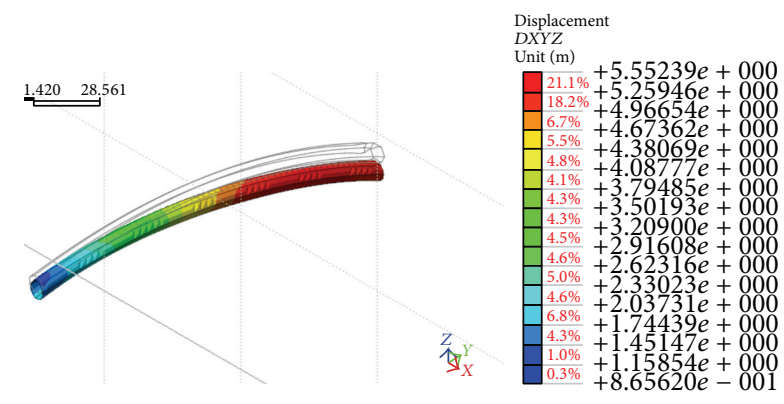

(b)
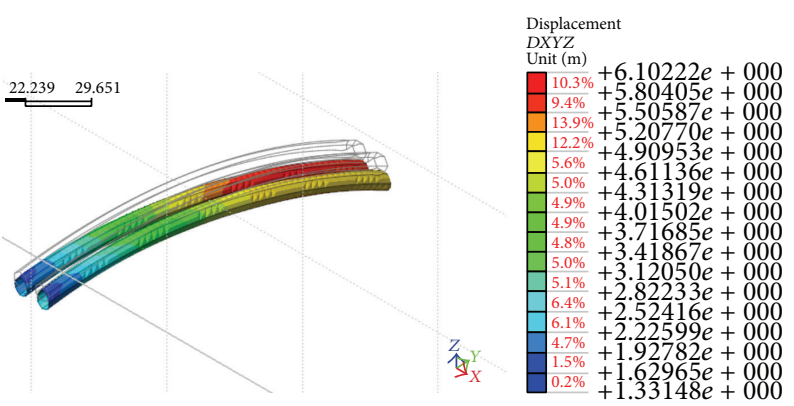

(d)
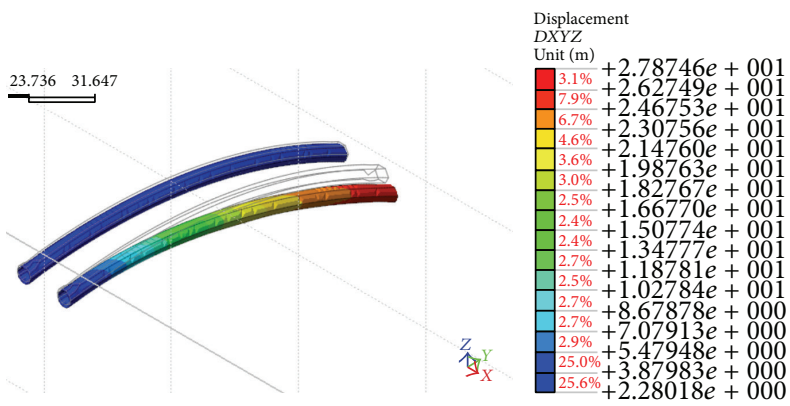

(f)

FIGURE 10: Deformed diagram of single and double bend pipeline due to PGD at the end of the nonlinear static analysis. (a) Burial depth = $0.5 D$, (b) burial depth $=D$, (c) burial depth $=2 D$, (d) spacing $=0.5 D$, (e) spacing $=D$, and (f) spacing $=2 D$.

type of pipe material can also lessen the effect of earthquake induced PGD.

\section{Conflict of Interests}

The authors declare that there is no conflict of interests regarding the publication of this paper.

\section{References}

[1] C. Scawthorn and P. I. Yanev, "Preliminary report 17 January 1995, 'Hyogo-ken Nambu , Japanese Earthquake,'” Engineering Structures, vol. 17, no. 3, pp. 146-157, 1995.

[2] T. D. O'Rourke, T. E. Gowdy, H. E. Stewart, and J. W. Pease, "Lifeline and geotechnical aspects of the 1989 Loma Prieta Earhquake," in Proceedings of the 2nd International Conference on Recent Advances in Geotechnical Earthquake Engineering and Soil Dynamics, pp. 1601-1612, University of Missouri-Rolla, Rolla, Mo, USA, 1991.
[3] A. J. Schiff, Northridge Earthquake: Lifeline Performance and Post-Earthquake Response, Technical Council on Lifeline Earthquake Engineering ASCE, 1997.

[4] M. Shinozuka, D. Ballantyne, R. Borcherdt, I. Buckle, T. O'Rourke, and A. Schiff, "The Hanshin-Awaji earthquake of January 17, 1995. Performance of lifeline," Tech. Rep., NCEER, Buffalo, NY, USA, 1995.

[5] H. S. Chou, C. Y. Yang, B. J. Hsieh, and S. S. Chang, "A study of liquefaction related damages on shield tunnels," Tunnelling and Underground Space Technology, vol. 16, no. 3, pp. 185-193, 2001.

[6] Y. Yong, "Response of pipeline structure subjected to ground motion excitation," Engineering Structures, vol. 19, no. 8, pp. 679-684, 1997.

[7] T. K. Datta, "Seismic response of buried pipelines: a state-ofthe-art review," Nuclear Engineering and Design, vol. 192, no. 2, pp. 271-284, 1999.

[8] Y. S. Karinski and D. Z. Yankelevsky, "Dynamic analysis of an elastic-plastic multisegment lining buried in soil," Engineering Structures, vol. 29, no. 3, pp. 317-328, 2007. 
[9] D. H. Lee, B. H. Kim, H. Lee, and J. S. Kong, "Seismic behavior of a buried gas pipeline under earthquake excitations," Engineering Structures, vol. 31, no. 5, pp. 1011-1023, 2009.

[10] R. P. Kennedy, A. W. Chow, and R. A. Williamson, "Fault movement effects on buried oil pipeline," Journal of the Transportation Engineering Division, vol. 103, no. TE5, pp. 617-633, 1977.

[11] N. M. Newmark and W. J. Hall, "Pipeline design to resist large fault displacement," in Proceedings of the 1st U.S. National Conference on Earthquake Engineering, pp. 416-425, Ann Arbor, Mich, USA, June 1975.

[12] T. D. O'Rourke and C. H. Tratumann, "Buried pipeline response to permanent earthquake ground movements," in Proceedings of the ASME Pressure Vessels and Piping Conference, San Francisco, Calif, USA, August 1980.

[13] W. F. Heubach, "Seismic screening checklists for water and waste water facilities," Monograph 22, Technical Council on Lifeline Earthquake Engineering, 2002.

[14] J. Eidinger and C. A. Davis, Recent Earthquakes: Implications for U.S. Water Utilities, Water Research Foundation, 2012.

[15] T. D. O'Rourke and P. A. Lane, "Liquefaction hazards and their effects on buried pipelines," Tech. Rep. NCEER-89-0007, National Center for Earthquake Engineering Research, Buffalo, NY, USA, 1989.

[16] T. D. O'Rourke and M. C. Palmer, "Earthquake performance of gas transmission pipelines," Earthquake Spectra, vol. 12, no. 3, pp. 493-527, 1996.

[17] R. T. Eguchi, "Earthquake performance of water supply components during the 1971 San Fernando Earthquake," Tech. Rep. 1396-2a, Wiggins JH Company, Redondo Beach, Calif, USA, 1982.

[18] MIDAS/GTS, "Modeling, integrated design analysis software (2013) - a geotechnical and tunnel analysis system," State-ofthe-Art Finite Element and Graphical Technology Manual GTS (v1.1), 2013.

[19] H. Tajika, H. Horikawa, and N. Suzuki, "Analysis of buried pipeline due to liquefaction-induced permanent ground deformation," in Proceedings of the International Gas Union Research Conference (IGRC '08), pp. 1-12, Paris, France, October 2008.

[20] M. Azadi and S. M. Mir Mohammad Hosseini, "The uplifting behavior of shallow tunnels within the liquefiable soils under cyclic loadings," Tunnelling and Underground Space Technology, vol. 25, no. 2, pp. 158-167, 2010. 

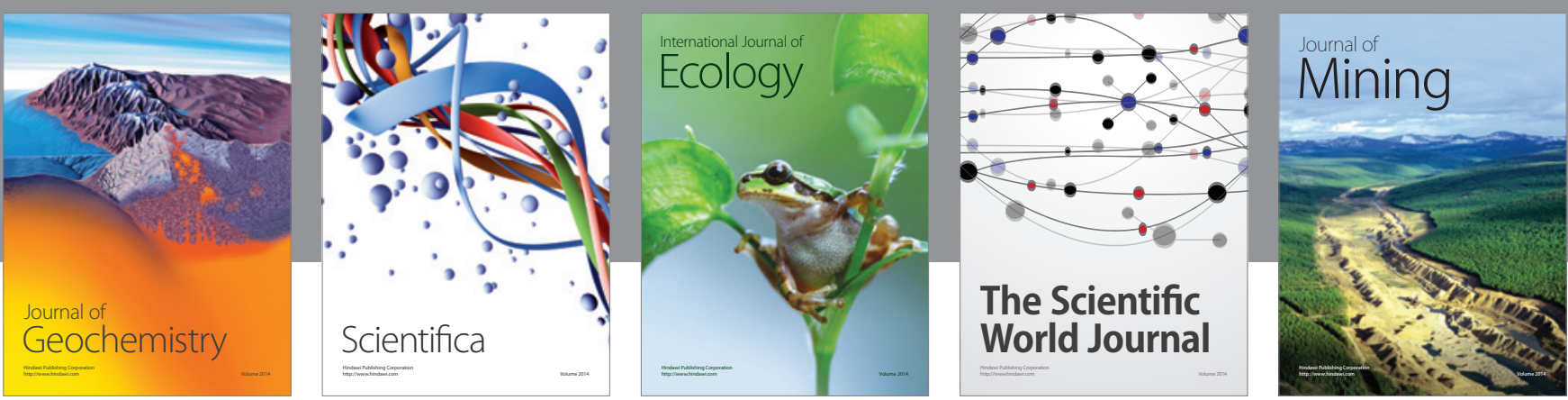

The Scientific World Journal
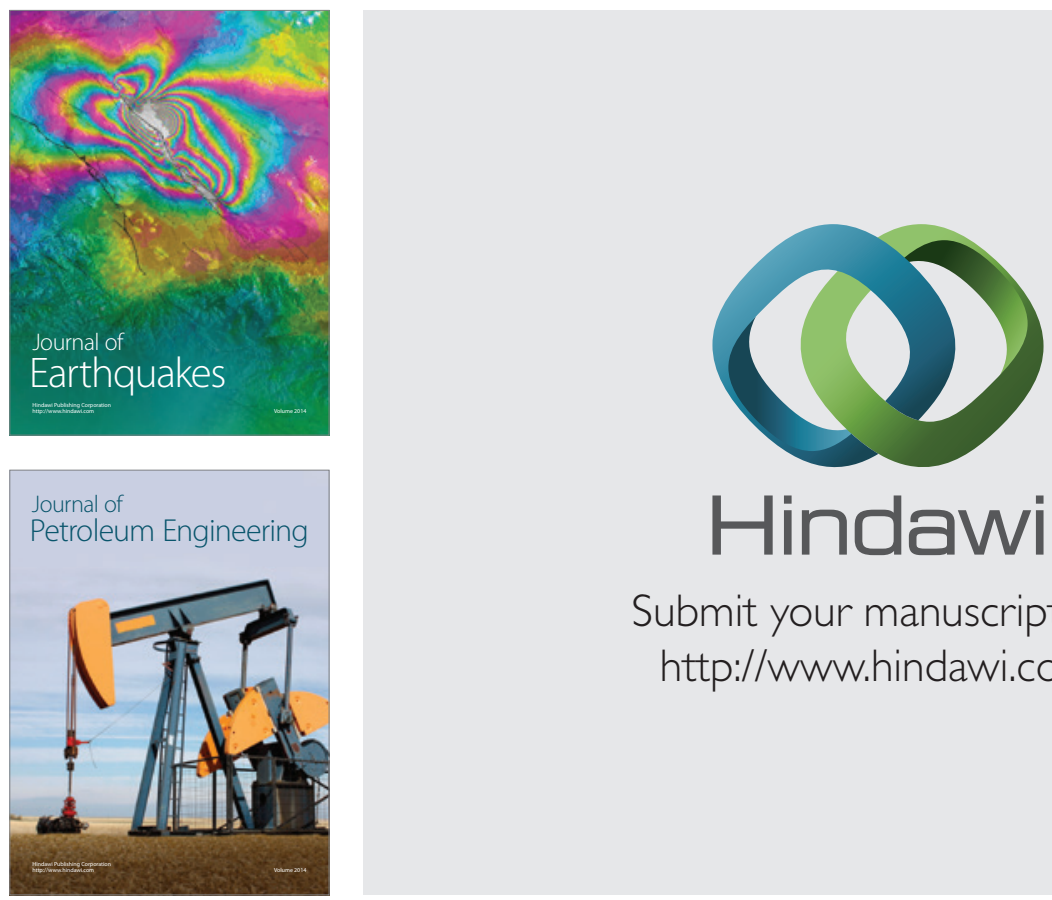

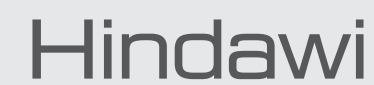

Submit your manuscripts at

http://www.hindawi.com
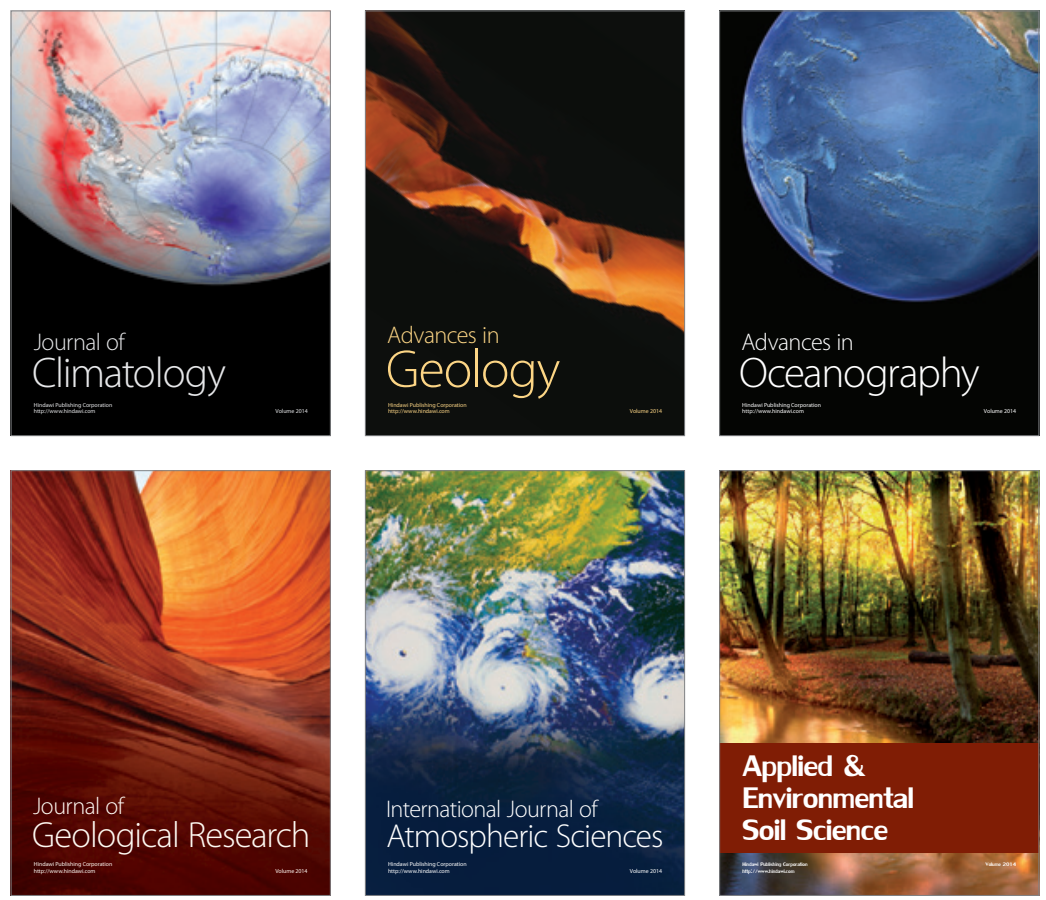
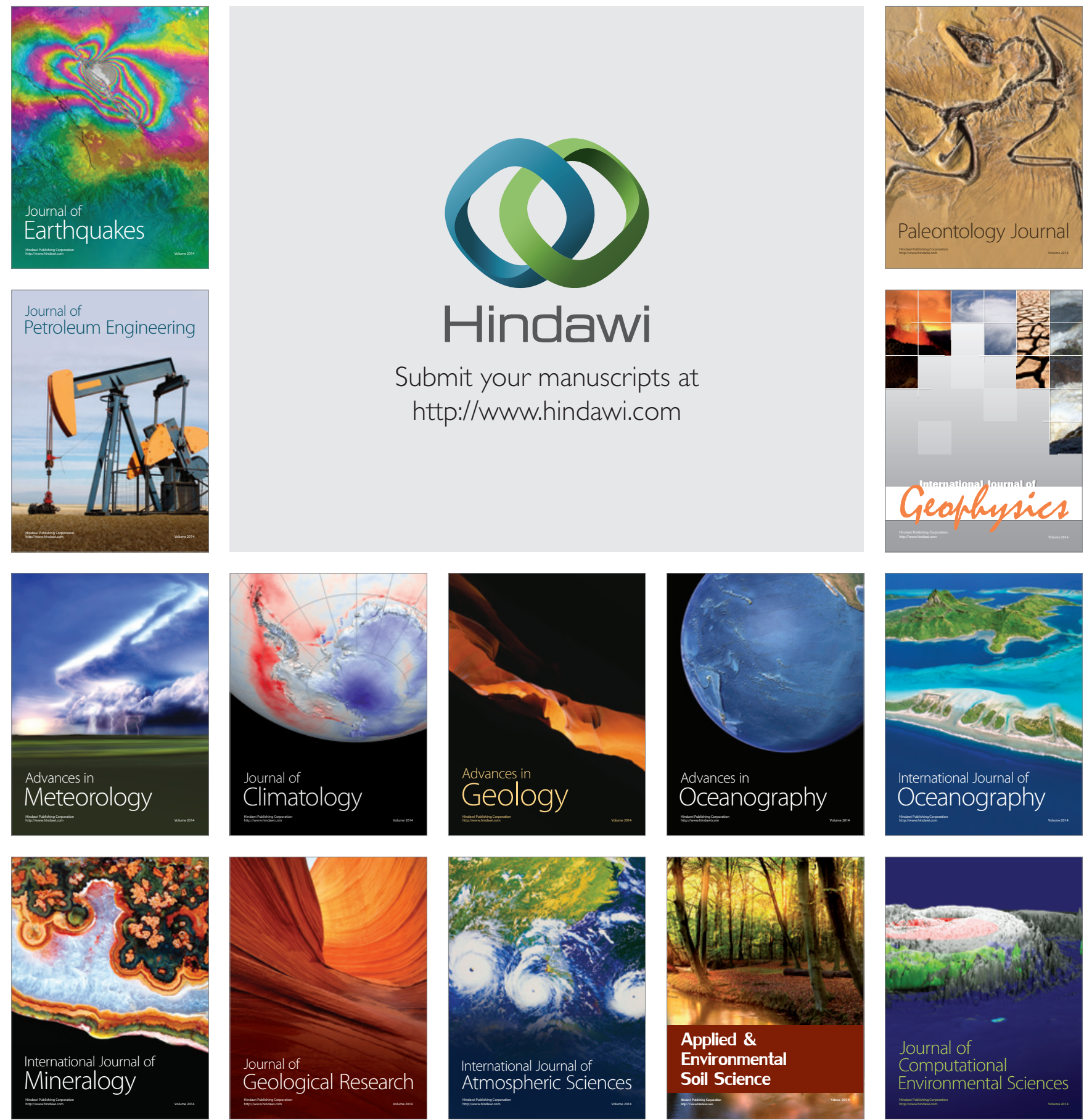